\title{
Interspecific Communal Oviposition by the Native Puerto Rican Eyespotted Geckolet (Sphaerodactylus macrolepis) and Invasive House Gecko (Hemidactylus sp.) in Puerto Rico
}

Alberto R. Estrada ${ }^{1}$ and Rafael Borroto-Páez ${ }^{2}$

Tnterspecific communal oviposition (ICO) is less frequently observed than conspecific communal oviposition (CCO), which is relatively common in many lizards, especially geckos (e.g., Rivero 1998; Krysko et al. 2003; Doody et al. 2009; Alfonso et al. 2012; Bernstein et al. 2016). We are aware of only one previous report by Krysko et al. (2003) of an ICO involving invasive and native species of geckos (e.g., invasive Hemidactylus and native Sphaerodactylus).

We encountered examples of communal oviposition between 1000 and $1030 \mathrm{~h}$ on 10 July 2003 in a stand of invasive Australian Pines (Casuarina equisetifolia) on the southern side of Route PR-187 in the western sector of the Piñones

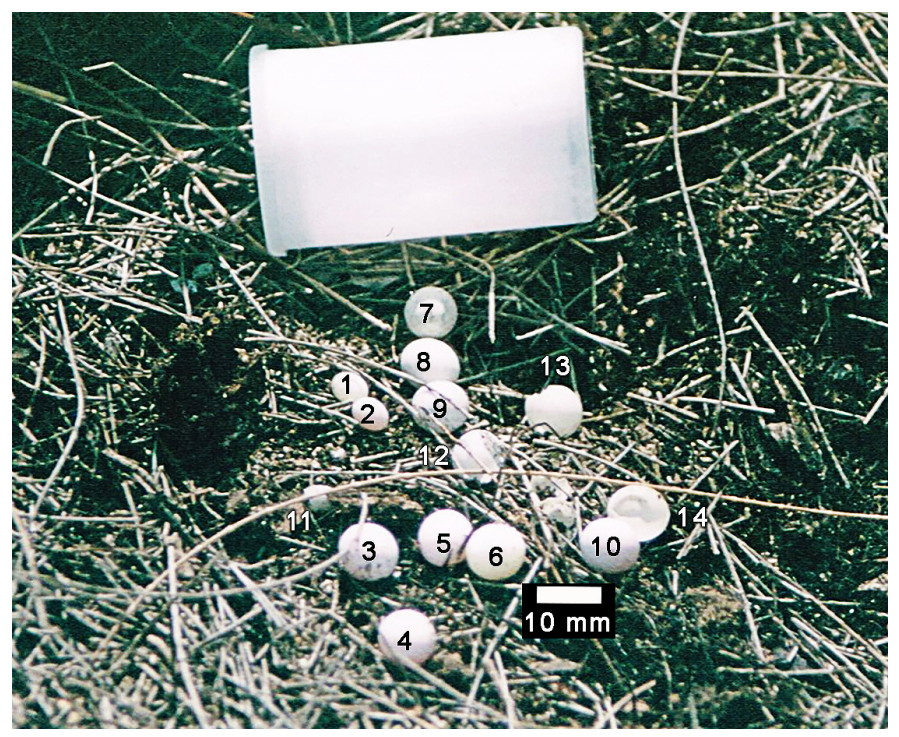

Fig 1. Interspecific communal oviposition site (14 eggs) of house geckos (Hemidactylus sp.) (11 large eggs) and Puerto Rican Eyespotted Geckolets (Sphaerodactylus macrolepis) (3 small eggs) under dry logs on leaf litter comprised of dry twigs of Australian Pine (Casuarina equisetifolia) in the western sector of the Piñones State Forest. Eggs 11 (S. macrolepis) and 12, 13, and 14 (Hemidactylus sp.) have hatched. Photograph by the senior author.

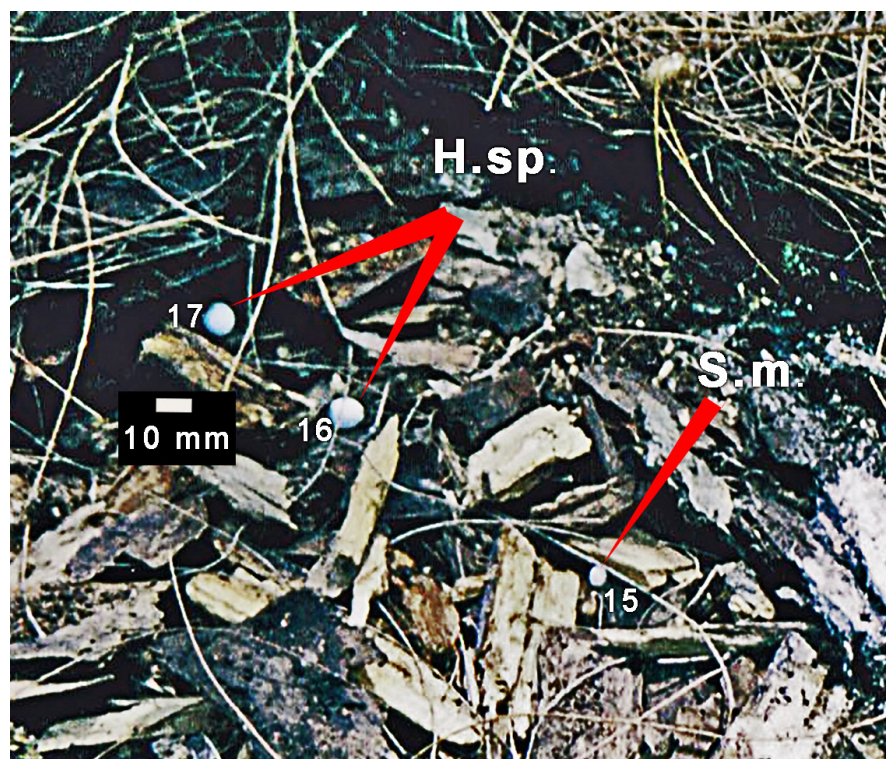

Fig 2. A second interspecific communal oviposition site (3 eggs) of house geckos (Hemidactylus sp.) and Puerto Rican Eyespotted Geckolets (Sphaerodactylus macrolepis) in Australian Pine (Casuarina equisetifolia) litter in the Piñones State Forest, Puerto Rico. Photograph by the senior author.

State Forest (18²7'10.74”N, 6558'08.81”W). The most frequently encountered geckos at this locality are native Puerto Rican Eyespotted Geckolet (Sphaerodactylus macrolepis) and the invasive Tropical House Geckos (Hemidactylus mabouia). Eggs were collected in hopes of recording data on hatchlings, but all were contaminated by fungi and were not viable.

We found two ICO sites involving Sphaerodactylus macrolepis and Hemidactylus sp. (probably $H$. mabouia) under dry logs on leaf litter comprised of dry twigs of the invasive Australian Pine tree (Figs. $1 \&$ 2). The first contained 14 eggs, three of $S$. macrolepis, one of them hatched, and 11 of Hemidactylus sp., three of which had hatched (Fig. 1). The 
Table 1. Sizes and shapes of eggs of Puerto Rican Eyespotted Geckolets (Sphaerodactylus macrolepis) and house geckos (Hemidactylus sp.) in two interspecific communal oviposition (ICO) sites and one conspecific communal oviposition (CCO) site in Australian Pine (Casuarina equisetifolia) litter in the Piñones Stare Forest, Puerto Rico. All measurements are in mm. Means are presented \pm one standard deviation. Numbers of eggs as in Figs. 1-3. S.m. = Sphaerodactylus macrolepis. H.sp. = Hemidactylus sp.

\begin{tabular}{|c|c|c|c|c|c|}
\hline Site & Species & Number & $\begin{array}{l}\text { Minimum } \\
\text { Diameter }\end{array}$ & $\begin{array}{l}\text { Maximum } \\
\text { Diameter }\end{array}$ & $\begin{array}{l}\text { Min/Max } \\
\text { Diameter }\end{array}$ \\
\hline \multirow[t]{10}{*}{ ICO 1} & S. m. & 1 & 4.9 & 6.9 & 0.71 \\
\hline & & 2 & 4.4 & 6.4 & 0.69 \\
\hline & H. sp. & 3 & 9.9 & 10.4 & 0.96 \\
\hline & & 4 & 8.9 & 9.9 & 0.90 \\
\hline & & 5 & 8.8 & 9.4 & 0.94 \\
\hline & & 6 & 9.4 & 9.9 & 0.95 \\
\hline & & 7 & 7.9 & 8.8 & 0.89 \\
\hline & & 8 & 8.8 & 10.4 & 0.85 \\
\hline & & 9 & 8.8 & 9.4 & 0.95 \\
\hline & & 10 & 9.4 & 10.4 & 0.90 \\
\hline \multirow[t]{3}{*}{ ICO 2} & S. m. & 15 & 5.2 & 6.2 & 0.84 \\
\hline & H. sp. & 16 & 8.6 & 10.0 & 0.86 \\
\hline & & 17 & 9.0 & 10.5 & 0.86 \\
\hline \multirow[t]{3}{*}{$\mathrm{CCO}$} & H. sp. & 18 & 8.4 & 9.8 & 0.86 \\
\hline & & 19 & 10.2 & 10.7 & 0.95 \\
\hline & & 20 & 9.6 & 10.5 & 0.91 \\
\hline \multirow[t]{2}{*}{ All } & S. m. & $\mathrm{n}=3$ & $4.83 \pm 0.40$ & $6.5 \pm 0.36$ & $0.75 \pm 0.08$ \\
\hline & H. sp. & $\mathrm{n}=13$ & $9.05 \pm 0.63$ & $10.0 \pm 0.55$ & $0.91 \pm 0.04$ \\
\hline
\end{tabular}

second ICO had only three eggs, two of Hemidactylus sp. and one of $S$. macrolepis (Fig. 2). Table 1 provides the sizes of the intact eggs. Those of Sphaerodactylus are smaller and more ovoid, whereas those of Hemidactylus are twice as large and rounded. The eggs of both species are white, smooth, and have fragile shells.

If we consider an interclutch interval of 16 days (Bock 1996), an incubation time of two months, and a clutch size of two (Krysko et al. 2003) for H. mabouia, the 11 eggs (three hatched) at the first site could have been deposited by a single female over a period of about three months. Alternatively, considering a clutch size of one for S. macrolepis (S.B. Hedges in Henderson and Powell 2009), a maximum number of females would be three $S$. macrolepis and six Hemidactylus sp. The second ICO with only three eggs must have involved only one female of each species. We also found a CCO of Hemidactylus sp. (probably H. mabouia) within $\sim 4 \mathrm{~m}$ of the two ICOs (Fig. 3); it contained only four eggs deposited by one or two females.

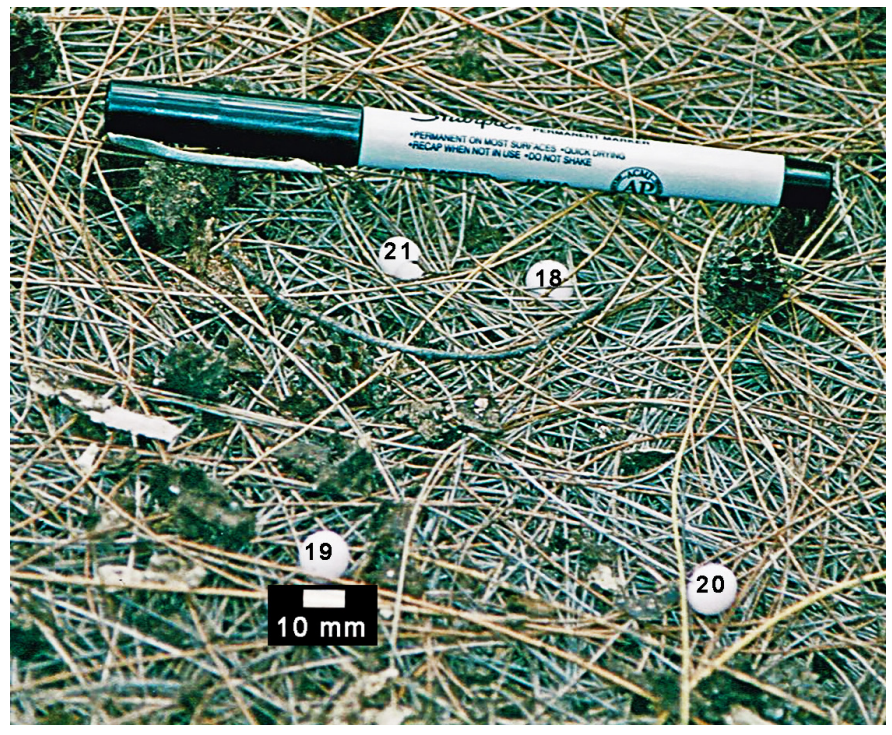

Fig 3. A conspecific communal oviposition site of house geckos (Hemidactylus sp.) in Australian Pine (Casuarina equisetifolia) litter in the Piñones State Forest, Puerto Rico. Egg 21 had hatched. Photograph by the senior author. 
The relative number of eggs in the two ICOs (13 Hemidactylus and four Sphaerodactylus) could be indicative of competitive interference, with use of a site by a female Hemidactylus suppressing the use of the same site by native Sphaerodactylus macrolepis. Lending some support to the latter contention are the difference in sizes of the two species (female SVL to $35 \mathrm{~mm}$ in S. macrolepis and $61 \mathrm{~mm}$ in $H$. mabouia; Henderson and Powell 2009) and observations by us of $H$. mabouia displacing $S$. elegans on walls of homes in Habana, Cuba.

In the Florida Keys, Krysko et al. (2003) described an ICO involving three invasive species (Hemidactylus frenatus, H. mabouia, and Sphaerodactylus elegans) and another ICO with two invasive species (H. mabouia and S. elegans) and a native species (S. notatus). Alfonso et al. (2012) described a Cuban ICO involving three native species $(S$. armasi, Tarentola crombiei, and Anolis argillaceus). In all three cases, the number of sphaerodactyl eggs was equal to or exceeded those of the other species. Bernstein et al. (2016) reported a CCO involving two species of Sphaerodactylus in Puerto Rico and the Bahamas and Rivero (1998) listed an example of a CCO involving sphaerodactyls in Puerto Rico. In all of these, the total number of eggs exceeded those in our observations.

The implication of native and invasive species engaging in communal oviposition is unknown. However, if an invasive species (like the larger house geckos in these instances) benefitted in some way (e.g., interference or competition for oviposition sites or other resources, predation on eggs or hatchlings; Bolger and Case 1992; Wickramasinghe and
Somaweera 2008; Kusuminda and Athukorala 2013), the potential negative effects on native species should receive more attention in future studies.

\section{Acknowledgements}

We thank Alberto Estrada Puerta and Omar Monzón for assistance during fieldwork.

\section{Literature Cited}

Alfonso, Y.U., P. Charruau, G. Fajardo, and A.R. Estrada. 2012. Interspecific communal oviposition and reproduction of three lizard species in southeastern Cuba. Herpetology Notes 5: 73-77.

Bernstein, J.M., A.H. Griffing, J.D. Daza, T. Gamble, and A.M. Bauer. 2016. Using alien resources: Caribbean dwarf geckos nesting communally in invasive flora. Reptiles \& Amphibians 23: 40-43.

Bock, B.C. 1996. Interclutch interval and egg aggregations in the Tropical House Gecko, Hemidactylus mabouia. Herpetological Review 27: 181-183.

Bolger, D.T. and T.J. Case.1992. Intra- and interspecific interference behaviour among sexual and asexual geckos. Animal Behaviour 44: 21-30.

Doody, J.S., S. Freedberg, and J.S. Keogh. 2009. Communal egg-laying in reptiles and amphibians: Evolutionary patterns and hypotheses. Quarterly Review in Biology 84: 229-252.

Henderson, R.W. and R. Powell. 2009. Natural History of West Indian Reptiles and Amphibians. University Press of Florida, Gainesville, Florida.

Krysko, K.L., C.M. Sheehy III, and A.N. Hooper. 2003. Interspecific communal oviposition and reproduction of four species of lizards (Sauria: Gekkonidae) in the lower Florida Keys. Amphibia-Reptilia 24: 390-396.

Kusuminda, T.G. and D. Athukorala. 2013. Egg-predation of Hemidactylus frenatus. Taprobanica 5: 152-153.

Rivero, J.A. 1998. Los Anfibios y Reptiles de Puerto Rico, segunda edición revisada. The Amphibians and Reptiles of Puerto Rico, second edition revised. Editorial de la Universidad de Puerto Rico, Río Piedras, Puerto Rico.

Wickramasinghe, M. and R. Somaweera. 2008. Changes in the distribution ranges of the Sri Lankan Hemidactylus geckos. Gekko 5: 44-60. 